\title{
Design and synthesis of chroman derivatives with dual anti-breast cancer and antiepileptic activities
}

This article was published in the following Dove Press journal:

Drug Design, Development and Therapy

2 September 2016

Number of times this article has been viewed

\section{Pinki Rawat \\ Saurabh Manaswita Verma}

Department of Pharmaceutical Sciences and Technology, Birla Institute of Technology, Mesra, Ranchi, Jharkhand, India
Correspondence: Pinki Rawat Department of Pharmaceutical Sciences and Technology, Birla Institute of Technology, Mesra, Ranchi 835215, Jharkhand, India

Tel +9l 9454855617

Email pnkrawat@yahoo.co.in
Abstract: A series of chroman derivatives was designed, prepared, and examined for their anti-breast cancer and antiepileptic activities. All synthesized compounds yielded results that were in good agreement with spectral data. The bioassay showed that some of the resultant compounds exerted remarkable inhibitory effects on growth of human breast cancer cell line MCF-7. In particular, compound $6 i$ (the concentration required for $50 \%$ inhibition of cell growth $\left.\left[\mathrm{GI}_{50}\right]=34.7 \mu \mathrm{M}\right)$ exerted promising anticancer activity toward MCF-7 cell line. Additionally, compounds $6 \mathrm{~b}, 6 \mathrm{c}, 6 \mathrm{~d}, 6 \mathrm{e}, 6 \mathrm{~g}, 6 \mathrm{i}$, and 61 showed advanced antiepileptic activity than reference drugs. None of the compounds showed neurotoxicity, as determined by the rotarod test. The obtained results proved that these distinctive compounds could be relevant as models for future discovery and research, as well as for the production of more number of active derivatives.

Keywords: anti-breast cancer, antiepileptic, chroman, isatin, Schiff base

\section{Introduction}

Breast cancer is one of the most commonly diagnosed cancers and is the second leading cause of death among women. ${ }^{1}$ Currently, a large number of chemotherapeutic agents are available, but toxicity and resistance to standard drug treatments limit the effectiveness of chemotherapy. Therefore, the search for new chemotherapeutic agents is an important task for researchers.

Heterocyclic compounds containing oxygen are presently considered very interesting due to their physicochemical properties being relevant as far as the design of new drugs is concerned. Literature reveals that chromans are an important chemical synthon, associated with a broad range of biological effects, neuroprotective, ${ }^{2}$ antiestrogens, ${ }^{3}$ antioxidant, ${ }^{4}$ anti-HIV,${ }^{5}$ and anti-breast cancer agents. ${ }^{6-8}$

Chromans have attracted a great deal of attention due to their anticancer activities since the discovery of Ormeloxifene (I), ${ }^{9}$ KBU2046 (Phase II), ${ }^{10}$ and B43-genistein (II) (Phase II; Figure 1). ${ }^{11}$ Furthermore, many chromans have contributed to the search for new anticancer agents. It has also been reported that Schiff base (III and IV) and isatin (V) moieties enhanced the anticancer activity of the chroman core. ${ }^{12,13}$

Epilepsy is a common neurological disorder affecting approximately 45-100 million people globally. ${ }^{14}$ Though many antiepileptic drugs are available in clinical use, neurotoxicity and distinctive adverse effects restrict their clinical use. ${ }^{15}$ Therefore, it is necessary to discover new chemical pharmacophores as more effective antiepileptics with less neurotoxicity. Literature has revealed that the presence of a Schiff base in a chroman nucleus (VI-VIII) is beneficial for the antiepileptic activity. ${ }^{16}$ Similarly, isatin (IX, X) being associated with a Schiff base accounts for its antiepileptic activity. ${ }^{17}$ 
<smiles>COc1ccc2c(c1)OC(C)(C)[C@H](C)[C@H]2c1ccc(OCCN2CCCC2)cc1</smiles><smiles>O=c1c(-c2ccc(O)cc2)coc2cc(O)cc(O)c12</smiles>

II-Genistein<smiles>[R]c1ccccc1/N=C(\C)c1coc2ccccc2c1=O</smiles>

$\mathrm{III}-\mathrm{R}=\mathrm{OH}$

$\mathrm{IV}-\mathrm{R}=\mathrm{COOH}$<smiles>CCOC(=O)C1=C(C(=O)OCC)C2(c3ccccc3N)NC(=O)C1(C(=O)OCC)N2</smiles><smiles>[R]c1ccccc1C1CC(=N)c2ccccc2O1</smiles><smiles>NNC(=O)c1ccccc1Oc1ccccc1</smiles><smiles>[R]N=C1C(=O)Nc2ccccc21</smiles>

$\mathrm{VI}-\mathrm{R}=\mathrm{H}$

$\mathrm{VII}-\mathrm{R}=\mathrm{Cl}$

VIII-R $=\mathrm{NO}_{2}$
IX-R = 1-Napthyl

$\mathrm{X}-\mathrm{R}=$ Phenyl hydrazine<smiles>[R]Oc1ccc(C(=O)N[C@H]2COc3cccc(N4CCN(C)CC4)c3C2)cc1</smiles>

$\mathrm{XI}-\mathrm{R}=\mathrm{C}_{4} \mathrm{H}_{9}$ $\mathrm{XII-R}=\mathrm{CF}_{3}$<smiles>[R][R]c1cccc2c1N([R])C(=O)/C2=N\NC(=O)C1(C)CCc2c(C)c([R2])c(C)c(C)c2O1</smiles>

$6 a-q$

Figure I Reported and designed chromans and isatins as anticancer and antiepileptic agents (6a-q).

Reports also suggest that some anticancer compounds have been studied as antiepileptics. ${ }^{18}$ The anti-breast cancer potential of the voltage-gated sodium channel-blocking antiepileptic drug phenytoin has also been discussed by researchers. ${ }^{19}$ Chroman derivatives XI and XII have been investigated as voltage-gated sodium channels..$^{20}$ Therefore, chroman analogs designed as anticancer agents may have antiepileptic activity also.

In this study, advances are made in designing chroman derivatives by adding Schiff base and isatin moieties at the second position. Seven compounds with antimicrobial activity have been reported in a previous work. ${ }^{21} \mathrm{~A}$ series of chroman compounds (6a-q) have been designed, synthesized, and their anti-breast cancer and antiepileptic activities evaluated.

\section{Materials and methods Materials}

All commercial chemicals were purchased from SigmaAldrich (St Louis, MO, USA) and Spectrochem (Mumbai, India). Thin layer chromatography was performed on plates precoated with silica gel GF-254 (Merck Millipore, Billerica, MA, USA), and the identification was done under UV light and spraying with charring solution, followed by heating. Melting points were determined in open glass capillaries and the uncorrected. NMR spectra were recorded on ECX-500 spectrometer (JEOL, Toko, Japan) in dimethyl sulfoxide (DMSO)- $\mathrm{d}_{6}$ and deuterated chloroform $\left(\mathrm{CDCl}_{3}\right)$ at $400 \mathrm{MHz}$ and $500 \mathrm{MHz}$ for ${ }^{1} \mathrm{H}$ and $125 \mathrm{MHz}$ for ${ }^{13} \mathrm{C}$. The chemical shifts were recorded in $(\delta, \mathrm{ppm})$ relative to tetramethylsilane as an internal standard. The mass spectra 
were recorded with a Waters-Q-Tof Premier-HAB213 spectrometer and Microscopic II triple-quadrupole mass spectrometer using electron ionization, and the $\mathrm{m} / \mathrm{z}$ values are indicated in daltons. The infrared (IR) spectra (KBr) were recorded on an FTIR Vector 22 spectrophotometer (Bruker Corporation, Billerica, MA, USA). Supplementary materials show ${ }^{1} \mathrm{H}$ and ${ }^{13} \mathrm{C}$ NMR spectra, FT-IR spectra, and mass spectra of compounds $\mathbf{6 a}-\mathbf{q}$ associated with this article.

\section{Synthesis of compounds}

6-Hydroxy-2,5,7,8-tetramethyl-chroman-2-carboxylic acid methyl ester $(3 \mathrm{a})$

6-Hydroxy-2,5,7,8-tetramethyl-chroman-2-carboxylic acid methyl ester (3a) was prepared by the method provided in the literature. ${ }^{22}$

6-Methoxy-2,5,7,8-tetramethyl-chroman-2-carboxylic acid methyl ester (3b)

To a solution of $3 \mathrm{a}(100 \mathrm{mg}, 40.0 \mathrm{mmol})$ in $10 \mathrm{~mL}$ anhydrous acetone, $2 \mathrm{~g}$ anhydrous $\mathrm{K}_{2} \mathrm{CO}_{3}$ was added and the mixture was heated at $50^{\circ} \mathrm{C}$. Dimethyl sulfate $(0.17 \mathrm{~mL}, 1.80 \mathrm{mmol})$ was then added, and the mixture was refluxed for 24 hours. After completion of the reaction, $\mathrm{HCl} \mathrm{10 \%} \mathrm{was} \mathrm{added} \mathrm{until}$ pH 6 and then extracted with diethylether. The organic layer was washed with saturated aqueous $\mathrm{NaCl}$ and dried, and the solvent was evaporated in vacuo. Purification by column chromatography (petroleum ether/EtOAc: 90/10) yielded $111 \mathrm{mg}(100 \%)$ white solid.

Methyl-6-(benzyloxy)-2,5,7,8-tetramethyl-3,4dihydro-2H-chromene-2-carboxylate (3c)

To a mixture of $3 \mathrm{a}(2 \mathrm{~g}, 7.566 \mathrm{mmol})$ and $\mathrm{K}_{2} \mathrm{CO}_{3}(1.568 \mathrm{~g}$, $11.349 \mathrm{mmol}$ ) was added with stirring $30 \mathrm{~mL}$ of dimethylformamide at $0^{\circ} \mathrm{C}$ for 20 minutes. Benzyl bromide $(1.553 \mathrm{~g}$, $9.080 \mathrm{mmol}$ ) was added to the reaction solution and stirred at room temperature overnight. The reaction mixture was diluted with $50 \mathrm{~mL}$ cold water, filtered, and washed with cold water to give a white solid (81.67\%).

General method for the synthesis of 6-substituted2,5,7,8-tetramethyl-3,4-dihydro-2H-chromene-2carbohydrazide $(4 a-c)$

Compounds $3 \mathrm{a}-\mathrm{c}(1 \mathrm{mmol})$ and $80 \%$ hydrazine hydrate $(5 \mathrm{mmol})$ in $10 \mathrm{~mL}$ ethanol were refluxed at $80^{\circ} \mathrm{C}$ for 10 hours. While the reaction proceeded, the ethanol was evaporated. The separated solid was filtered, washed with water, and dried to obtain a dull white solid.
General method for the synthesis of the final compounds $(6 a-q)$

The compounds were prepared through the condensation reaction between $5 \mathrm{a}-\mathrm{q}(1 \mathrm{mmol})$ and $4 \mathrm{a}-\mathrm{c}(1 \mathrm{mmol})$ in $10 \mathrm{~mL}$ acetic acid under reflux at $120^{\circ} \mathrm{C}$ for $3-12$ hours. Then, $20 \mathrm{~mL}$ distilled water was added into the reaction medium. The compounds were filtered and recrystallized in ethanol.

6-Hydroxy-2,5,7,8-tetramethyl-N'-(2oxoindolin-3-ylidene)-3,4-dihydro-2H-chromene-2carbohydrazide (6a)

Yield: Yellow solid (74\%); melting point (MP): $240^{\circ} \mathrm{C}$; IR (KBr, v, $\left.\mathrm{cm}^{-1}\right):$ 3,426 (NH), 3,227 (OH), 1,694 (CO); ${ }^{1} \mathrm{H}-\mathrm{NMR}$ (500 MHz, DMSO-d, ppm): 11.17 (s, 1H, -NH), 7.52 (s, 1H, OH), 7.48 (d, $J=7.3 \mathrm{~Hz}, 1 \mathrm{H}), 7.32$ (t, $J=7.6 \mathrm{~Hz}$, $1 \mathrm{H}), 7.03(\mathrm{t}, J=7.6 \mathrm{~Hz}, 1 \mathrm{H}), 6.86(\mathrm{~d}, J=7.6 \mathrm{~Hz}, 1 \mathrm{H}), 2.59-2.54$ $(\mathrm{m}, 1 \mathrm{H}), 2.47-2.45(\mathrm{~m}, 1 \mathrm{H}), 2.28-2.25(\mathrm{~m}, 1 \mathrm{H}), 2.18(\mathrm{~s}, 3 \mathrm{H})$, $2.04(\mathrm{~s}, 3 \mathrm{H}), 1.96(\mathrm{~s}, 3 \mathrm{H}), 1.86-1.81(\mathrm{~m}, 1 \mathrm{H}), 1.47(\mathrm{~s}, 3 \mathrm{H})$; ${ }^{13} \mathrm{C}-\mathrm{NMR}\left(125 \mathrm{MHz}, \mathrm{DMSO}-\mathrm{d}_{6}\right) 12.3\left(-\mathrm{CH}_{3}\right), 12.5\left(-\mathrm{CH}_{3}\right)$, $13.3\left(-\mathrm{CH}_{3}\right), 20.4\left(-\mathrm{CH}_{2}\right), 24.7\left(-\mathrm{CH}_{3}\right), 29.6\left(-\mathrm{CH}_{2}\right), 78.1$ $(>\mathrm{C}<), 111.6,117.2,120.2,120.8,121.4,122.2,123.1$, $123.5,132.3,139.1,143.1,143.8,146.7,162.9(>\mathrm{C}=\mathrm{O})$, $171.9(>\mathrm{C}=\mathrm{O})$; high-resolution mass spectrometry (HR-MS): 394.1700 (M+H) ${ }^{+}$, calculated: 394.1766.

6-hydroxy-2,5,7,8-tetramethyl-N'-(I -methyl-2-oxoindolin3-ylidene)-3,4-dihydro-2H-chromene-2-

carbohydrazide (6b)

Yield: Yellow solid (72\%), MP: $237^{\circ} \mathrm{C}$; IR $\left(\mathrm{KBr}, \mathrm{v}, \mathrm{cm}^{-1}\right)$ : 3,406 (OH), 3,261 (NH), 1,683 (CO); ${ }^{1} \mathrm{H}-\mathrm{NMR}(500 \mathrm{MHz}$, DMSO-d $\left.{ }_{6}, \mathrm{ppm}\right): 7.54(\mathrm{~s}, 1 \mathrm{H}, \mathrm{OH}), 7.50(\mathrm{~d}, J=7.3 \mathrm{~Hz}, 1 \mathrm{H}), 7.40$ ( $\mathrm{t}, J=7.6 \mathrm{~Hz}, 1 \mathrm{H}), 7.10-7.05(\mathrm{~m}, 2 \mathrm{H}), 3.13(\mathrm{~s}, 3 \mathrm{H}), 2.59-2.54$ (m, 1H), 2.50-2.44 (m, 1H), 2.29-2.23 (m, 1H), 2.21 (s, 3H), 2.05 (s, 3H), $1.96(\mathrm{~s}, 3 \mathrm{H}), 1.87-1.81(\mathrm{~m}, 1 \mathrm{H}), 1.47$ $(\mathrm{s}, 3 \mathrm{H}) ;{ }^{13} \mathrm{C}-\mathrm{NMR}\left(125 \mathrm{MHz}, \mathrm{DMSO}-\mathrm{d}_{6}\right) 12.3\left(-\mathrm{CH}_{3}\right)$, $12.5\left(-\mathrm{CH}_{3}\right), 13.3\left(-\mathrm{CH}_{3}\right), 20.4\left(-\mathrm{CH}_{2}\right), 24.6\left(-\mathrm{CH}_{3}\right), 26.1$ $\left(>\mathrm{N}-\mathrm{CH}_{3}\right), 29.6\left(-\mathrm{CH}_{2}\right), 78.1(>\mathrm{C}<), 110.2,117.3,119.5$, 120.8, 121.0, 122.2, 123.5, 123.6, 132.2, 138.2, 143.8, 144.3, 146.83, $161.0(>\mathrm{C}=\mathrm{O}), 171.9(>\mathrm{C}=\mathrm{O})$; HR-MS: 408.1926 $(\mathrm{M}+\mathrm{H})^{+}$, calculated, 408.4702 .

$\mathrm{N}^{\prime}$-(5-chloro-2-oxoindolin-3-ylidene)-6-hydroxy-2,5,7,8tetramethyl-3,4-dihydro-2H-chromene-2-

carbohydrazide (6c)

Yield: Light Yellow solid (87\%), MP: $255^{\circ} \mathrm{C}$; IR (KBr, $\left.v, \mathrm{~cm}^{-1}\right): 3,598(\mathrm{NH}), 3,151(\mathrm{OH}), 1,680(\mathrm{CO}) ;{ }^{1} \mathrm{H}-\mathrm{NMR}$ (500 MHz, DMSO-d 6 , ppm): 11.28 (s, 1H, -NH), 7.54 (s, 
$1 \mathrm{H}, \mathrm{OH}), 7.46(\mathrm{~d}, J=2.1 \mathrm{~Hz}, 1 \mathrm{H}), 7.35(\mathrm{dd}, J=2.1,8.2 \mathrm{~Hz}$, $1 \mathrm{H}), 6.88(\mathrm{~d}, J=8.2 \mathrm{~Hz}, 1 \mathrm{H}), 2.60-2.54(\mathrm{~m}, 1 \mathrm{H}), 2.47-2.43$ (m, 1H), 2.30-2.24 (m, 1H), $2.17(\mathrm{~s}, 3 \mathrm{H}), 2.04(\mathrm{~s}, 3 \mathrm{H}), 1.96$ $(\mathrm{s}, 3 \mathrm{H}), 1.86-1.80(\mathrm{~m}, 1 \mathrm{H}), 1.47(\mathrm{~s}, 3 \mathrm{H}) ;{ }^{13} \mathrm{C}-\mathrm{NMR}(125$ $\left.\mathrm{MHz}, \mathrm{DMSO}-\mathrm{d}_{6}\right) 12.3\left(-\mathrm{CH}_{3}\right), 12.4\left(-\mathrm{CH}_{3}\right), 13.3\left(-\mathrm{CH}_{3}\right)$, $20.3\left(-\mathrm{CH}_{2}\right), 24.6\left(-\mathrm{CH}_{3}\right), 29.5\left(-\mathrm{CH}_{2}\right), 78.1(>\mathrm{C}<), 113.1$, 117.2, 120.8, 120.9, 122.0, 122.2, 123.5, 127.2, 131.7, 138.2, 141.8, 143.8, 146.8, $162.7(>\mathrm{C}=\mathrm{O}), 172.0(>\mathrm{C}=\mathrm{O})$; HR-MS: $450.1377(\mathrm{M}+\mathrm{H})^{+}$, calculated, 450.1196.

N'-(5-bromo-2-oxoindolin-3-ylidene)-6-hydroxy-2,5,7,8tetramethyl-3,4-dihydro-2H-chromene-2-

carbohydrazide (6d)

Yield: Yellow solid (56\%), MP: $260^{\circ} \mathrm{C}$; IR (KBr, v, $\left.\mathrm{cm}^{-1}\right)$ : 3,594 (NH), 3,149 (OH), 1,680 (CO); ${ }^{1} \mathrm{H}-\mathrm{NMR}(500 \mathrm{MHz}$, DMSO-d, ppm): 11.30 (s, 1H, -NH), 7.56 (s, 1H,), 7.54 $(\mathrm{s}, 1 \mathrm{H}, \mathrm{OH}), 7.48(\mathrm{~d}, J=8.0 \mathrm{~Hz}, 1 \mathrm{H}), 6.83(\mathrm{~d}, J=8.0 \mathrm{~Hz}, 1 \mathrm{H})$, 2.60-2.54 (m, 1H), 2.47-2.43 (m, 1H), 2.29-2.24 (m, 1H), $2.17(\mathrm{~s}, 3 \mathrm{H}), 2.03(\mathrm{~s}, 3 \mathrm{H}), 1.96(\mathrm{~s}, 3 \mathrm{H}), 1.86-1.80(\mathrm{~m}$, 1H), 1.47 (s, 3H); ${ }^{13} \mathrm{C}-\mathrm{NMR}\left(125 \mathrm{MHz}, \mathrm{DMSO}-\mathrm{d}_{6}\right) 12.3$ $\left(-\mathrm{CH}_{3}\right), 12.4\left(-\mathrm{CH}_{3}\right), 13.3\left(-\mathrm{CH}_{3}\right), 20.3\left(-\mathrm{CH}_{2}\right), 24.6\left(-\mathrm{CH}_{3}\right)$, $29.5\left(-\mathrm{CH}_{2}\right), 78.1(>\mathrm{C}<), 113.5,114.8,117.2,120.8,122.2$, $122.4,123.5,123.7,134.5,138.1,142.1,143.8,146.8,162.6$ $(>\mathrm{C}=\mathrm{O}), 172.0(>\mathrm{C}=\mathrm{O})$; HR-MS: $494.0690(\mathrm{M}+\mathrm{Na})^{+}$, calculated, 494.0691.

N'-(6-chloro-2-oxoindolin-3-ylidene)-6-hydroxy-2,5,7,8tetramethyl-3,4-dihydro-2H-chromene-2-

carbohydrazide (6e)

Yield: Yellow solid (57\%), MP: $290^{\circ} \mathrm{C}$; IR ( $\left.\mathrm{KBr}, \mathrm{v}, \mathrm{cm}^{-1}\right)$ : 3,443 (NH), 3,141 (OH), 1,678 (CO); ${ }^{1} \mathrm{H}-\mathrm{NMR}(500 \mathrm{MHz}$, DMSO-d $\left.{ }_{6}, \mathrm{ppm}\right): 11.20(\mathrm{~s}, 1 \mathrm{H},-\mathrm{NH}), 7.54(\mathrm{~s}, 1 \mathrm{H}, \mathrm{OH})$, 7.29 (dd, $J=2.5,8.0 \mathrm{~Hz}, 1 \mathrm{H}), 7.19-7.14(\mathrm{~m}, 1 \mathrm{H}), 6.87-6.85$ (dd, $J=4.3,8.5 \mathrm{~Hz}, 1 \mathrm{H}), 2.60-2.54(\mathrm{~m}, 1 \mathrm{H}), 2.50-2.40(\mathrm{~m}$, 1H), 2.29-2.24 (m, 1H), $2.17(\mathrm{~s}, 3 \mathrm{H}), 2.03(\mathrm{~s}, 3 \mathrm{H}), 1.96(\mathrm{~s}$, 3H), 1.85-1.80 (m, 1H), 1.47 (s, 3H); HR-MS: 428.1372 $(\mathrm{M}+\mathrm{H})^{+}$, calculated, 428.1377 .

N'-(5-fluoro-2-oxoindolin-3-ylidene)-6-hydroxy-2,5,7,8tetramethyl-3,4-dihydro-2H-chromene-2-

carbohydrazide (6f)

Yield: Yellow solid (51\%), MP: $290^{\circ} \mathrm{C}$; IR $\left(\mathrm{KBr}, \mathrm{v}, \mathrm{cm}^{-1}\right)$ : 3,566 (NH), 3,206 (OH), 1,686 (CO); ${ }^{1} \mathrm{H}-\mathrm{NMR}(500 \mathrm{MHz}$, DMSO-d, ppm): $11.18(\mathrm{~s}, 1 \mathrm{H},-\mathrm{NH}), 7.52$ (s, 1H, OH), $7.29(\mathrm{dd}, J=2.5,8.0 \mathrm{~Hz}, 1 \mathrm{H}), 7.18-7.14(\mathrm{~m}, 1 \mathrm{H}), 6.86$ (dd, $J=4.3,8.6 \mathrm{~Hz}, 1 \mathrm{H}), 2.59-2.54(\mathrm{~m}, 1 \mathrm{H}), 2.50-2.42$ (m, 1H), 2.30-2.25 (m, 1H), $2.18(\mathrm{~s}, 3 \mathrm{H}), 2.04(\mathrm{~s}, 3 \mathrm{H}), 1.96$ $(\mathrm{s}, 3 \mathrm{H}), 1.86-1.80(\mathrm{~m}, 1 \mathrm{H}), 1.47(\mathrm{~s}, 3 \mathrm{H}) ;{ }^{13} \mathrm{C}-\mathrm{NMR}(125$ $\left.\mathrm{MHz}, \mathrm{DMSO}-\mathrm{d}_{6}\right) 12.3\left(-\mathrm{CH}_{3}\right), 12.4\left(-\mathrm{CH}_{3}\right), 13.3\left(-\mathrm{CH}_{3}\right)$,
$20.4\left(-\mathrm{CH}_{2}\right), 24.6\left(-\mathrm{CH}_{3}\right), 29.6\left(-\mathrm{CH}_{2}\right), 78.1(>\mathrm{C}<), 108.4$, 108.6, 112.6, 112.7, 117.2, 118.6, 118.8, 120.8, 121.5, 121.6, $122.2,123.5,138.7,139.4,143.8,146.8,157.8,159.7,163.1$ $(>\mathrm{C}=\mathrm{O}), 172.0(>\mathrm{C}=\mathrm{O})$; HR-MS: $412.1681(\mathrm{M}+\mathrm{H})^{+}$, calculated, 412.1672 .

N'-(6-chloro- I-methyl-2-oxoindolin-3-ylidene)-6hydroxy-2,5,7,8-tetramethyl-3,4-dihydro-2H-chromene-2carbohydrazide (6g)

Yield: Yellow solid (59\%), MP: $257^{\circ} \mathrm{C}$; IR (KBr, v, $\left.\mathrm{cm}^{-1}\right)$ : 3,479 (NH), 3,223 (OH), 1,697 (CO); ${ }^{1} \mathrm{H}-\mathrm{NMR}$ (500 MHz, DMSO-d, ppm): 7.54 (s, 1H, OH), 7.47-7.44 (m, 2H), $7.10(\mathrm{~d}, J=8.2 \mathrm{~Hz}, 1 \mathrm{H}), 3.13(\mathrm{~s}, 3 \mathrm{H}), 2.60-2.54(\mathrm{~m}, 1 \mathrm{H})$, 2.50-2.41 (m, 1H), 2.29-2.24 (m, 1H), $2.20(\mathrm{~s}, 3 \mathrm{H}), 2.04$ $(\mathrm{s}, 3 \mathrm{H}), 1.96(\mathrm{~s}, 3 \mathrm{H}), 1.87-1.81(\mathrm{~m}, 1 \mathrm{H}), 1.47(\mathrm{~s}, 3 \mathrm{H}) ;{ }^{13} \mathrm{C}-$ NMR (125 MHz, DMSO-d $) 12.2\left(-\mathrm{CH}_{3}\right), 12.5\left(-\mathrm{CH}_{3}\right), 13.3$ $\left(-\mathrm{CH}_{3}\right), 20.3\left(-\mathrm{CH}_{2}\right), 24.6\left(-\mathrm{CH}_{3}\right), 26.3\left(>\mathrm{N}-\mathrm{CH}_{3}\right), 29.5$ $\left(-\mathrm{CH}_{2}\right), 78.1(>\mathrm{C}<), 111.8,117.2,120.5,120.8,121.2$, $122.2,123.5,127.7,131.5,137.3,143.0,143.7,146.8,160.8$ $(>\mathrm{C}=\mathrm{O}), 172.0(>\mathrm{C}=\mathrm{O})$; HR-MS: $442.1537(\mathrm{M}+\mathrm{H})^{+}$, calculated, 442.1530 .

\section{6-Methoxy-2,5,7,8-tetramethyl-N'-(2-oxoindolin-3-} ylidene)-3,4-dihydro-2H-chromene-2-carbohydrazide (6h) Yield: Light Yellow solid (58\%), MP: $256^{\circ} \mathrm{C}$; IR ( $\mathrm{KBr}$, $\mathrm{v}, \mathrm{cm}^{-1}$ ): 3,184 (NH), 1,683 (CO); ${ }^{1} \mathrm{H}-\mathrm{NMR}(500 \mathrm{MHz}$, DMSO-d, ppm): 11.19 (s, 1H, -NH), 7.49 (d, J=7.3 Hz, 1H), 7.32 (t, J=7.6 Hz, 1H), 7.03 (t, J=7.6 Hz, 1H), 6.87 $(\mathrm{d}, J=8.0 \mathrm{~Hz}, 1 \mathrm{H}), 3.49\left(\mathrm{~s}, 3 \mathrm{H},-\mathrm{OCH}_{3}\right), 2.62-2.58(\mathrm{~m}$, $1 \mathrm{H}), 2.51-2.46(\mathrm{~m}, 1 \mathrm{H}), 2.29-2.23(\mathrm{~m}, 1 \mathrm{H}), 2.19(\mathrm{~s}, 3 \mathrm{H})$, $2.08(\mathrm{~s}, 3 \mathrm{H}), 2.01$ (s, 3H), 1.89-1.84 (m, 1H), 1.48 (s, 3H); ${ }^{13} \mathrm{C}-\mathrm{NMR}\left(125 \mathrm{MHz}, \mathrm{DMSO}-\mathrm{d}_{6}\right) 11.9\left(-\mathrm{CH}_{3}\right), 12.4\left(-\mathrm{CH}_{3}\right)$, $12.9\left(-\mathrm{CH}_{3}\right), 20.1\left(-\mathrm{CH}_{2}\right), 24.5\left(-\mathrm{CH}_{3}\right), 29.3\left(-\mathrm{CH}_{2}\right), 60.3$ $\left(-\mathrm{OCH}_{3}\right), 78.4(>\mathrm{C}<), 111.6,118.0,120.2,121.5,123.1$, 123.1, 126.0, 128.0, 132.4, 139.2, 143.1, 146.4, 150.5, 162.9 $(>\mathrm{C}=\mathrm{O}), 171.6(>\mathrm{C}=\mathrm{O})$; HR-MS: $408.1924(\mathrm{M}+\mathrm{H})^{+}$, calculated, 408.1923.

$\mathrm{N}^{\prime}$-(5-bromo-2-oxoindolin-3-ylidene)-6-methoxy-2,5,7,8tetramethyl-3,4-dihydro-2H-chromene-2-

carbohydrazide (6i)

Yield: Yellow solid (51\%), MP: $290^{\circ} \mathrm{C}$; IR (KBr, v, $\left.\mathrm{cm}^{-1}\right)$ : 3,194 (NH), 1,681 (CO); 'H-NMR (500 MHz, DMSO-d, ppm): 11.31 (s, 1H, -NH), 7.57 (s, 1H), 7.49 (d, J=8.2 Hz, $1 \mathrm{H}), 6.84(\mathrm{~d}, \mathrm{~J}=8.2 \mathrm{~Hz}, 1 \mathrm{H}), 3.48\left(\mathrm{~s}, 3 \mathrm{H},-\mathrm{OCH}_{3}\right), 2.61-2.57$ $(\mathrm{m}, 1 \mathrm{H}), 2.50-2.45(\mathrm{~m}, 1 \mathrm{H}), 2.30-2.23(\mathrm{~m}, 1 \mathrm{H}), 2.19(\mathrm{~s}, 3 \mathrm{H})$, $2.08(\mathrm{~s}, 3 \mathrm{H}), 2.01(\mathrm{~s}, 3 \mathrm{H}), 1.88-1.86(\mathrm{~m}, 1 \mathrm{H}), 1.48(\mathrm{~s}, 3 \mathrm{H})$; ${ }^{13} \mathrm{C}-\mathrm{NMR}\left(125 \mathrm{MHz}, \mathrm{DMSO}-\mathrm{d}_{6}\right) 11.9\left(-\mathrm{CH}_{3}\right), 12.4\left(-\mathrm{CH}_{3}\right)$, $12.9\left(-\mathrm{CH}_{3}\right), 20.1\left(-\mathrm{CH}_{2}\right), 24.5\left(-\mathrm{CH}_{3}\right), 29.2\left(-\mathrm{CH}_{2}\right), 60.3$ 
$\left(-\mathrm{OCH}_{3}\right), 78.4(>\mathrm{C}<), 113.6,114.8,118.0,122.4,123.0$, $123.7,126.1,128.0,134.5,138.2,142.1,146.3,150.6$, 162.6 $(>\mathrm{C}=\mathrm{O}), 171.7(>\mathrm{C}=\mathrm{O})$; HR-MS: $486.1027(\mathrm{M}+\mathrm{H})^{+}$, calculated, 486.1028 .

$N^{\prime}$-(5-fluoro-2-oxoindolin-3-ylidene)-6-methoxy-2,5,7,8tetramethyl-3,4-dihydro-2H-chromene-2-

carbohydrazide $(6 \mathrm{j})$

Yield: Yellow solid (66\%), MP: $>300^{\circ} \mathrm{C}$; IR $\left(\mathrm{KBr}, \mathrm{v}, \mathrm{cm}^{-1}\right)$ : 3,487 (NH), 1,684 (CO); ' H-NMR (500 MHz, DMSO-d, ppm): $11.21(\mathrm{~s}, 1 \mathrm{H},-\mathrm{NH}), 7.30(\mathrm{dd}, J=2.8,8.0 \mathrm{~Hz}, 1 \mathrm{H})$, 7.19-7.15 (m, 1H), 6.87 (dd, $J=4.3,8.5 \mathrm{~Hz}, 1 \mathrm{H}, 1 \mathrm{H}), 3.49$ $\left(\mathrm{s}, 3 \mathrm{H},-\mathrm{OCH}_{3}\right), 2.62-2.57(\mathrm{~m}, 1 \mathrm{H}), 2.50-2.45(\mathrm{~m}, 1 \mathrm{H})$, 2.27-2.22 (m, 1H), 2.19 (s, 3H), $2.08(\mathrm{~s}, 3 \mathrm{H}), 2.01(\mathrm{~s}, 3 \mathrm{H})$, $1.88-1.85(\mathrm{~m}, 1 \mathrm{H}), 1.48(\mathrm{~s}, 3 \mathrm{H}) ;{ }^{13} \mathrm{C}-\mathrm{NMR}(125 \mathrm{MHz}$, DMSO-d $)_{6} 11.9\left(-\mathrm{CH}_{3}\right), 12.4\left(-\mathrm{CH}_{3}\right), 12.9\left(-\mathrm{CH}_{3}\right), 20.1$ $\left(-\mathrm{CH}_{2}\right), 24.4\left(-\mathrm{CH}_{3}\right), 29.3\left(-\mathrm{CH}_{2}\right), 60.3\left(-\mathrm{OCH}_{3}\right), 78.4$ $(>\mathrm{C}<), 108.5,108.7,112.7,112.8,118.0,118.6,118.8$, $121.5,121.6,123.1,126.1,128.0,138.9,139.4,146.3$, 150.6, 157.8, 159.7, $163.1(>\mathrm{C}=\mathrm{O}), 171.7(>\mathrm{C}=\mathrm{O})$; HR-MS: $426.1822(\mathrm{M}+\mathrm{H})^{+}$, calculated, 426.1829.

$\mathrm{N}^{\prime}$-(6-chloro-2-oxoindolin-3-ylidene)-6-methoxy-2,5,7,8tetramethyl-3,4-dihydro-2H-chromene-2-

carbohydrazide (6k)

Yield: Yellow solid (52\%), MP: $270^{\circ} \mathrm{C}$; IR $\left(\mathrm{KBr}, \mathrm{v}, \mathrm{cm}^{-1}\right)$ : 3,207 (NH), 1,683 (CO); 'H-NMR (500 MHz, DMSO-d, ppm): 11.32 (s, 1H, -NH), 7.48 (d, J=8.0 Hz, 1H), 7.07 (d, J=8.0 Hz,1H), $6.90(\mathrm{~s}, 1 \mathrm{H}), 3.49\left(\mathrm{~s}, 3 \mathrm{H},-\mathrm{OCH}_{3}\right)$, 2.63-2.57 (m, 1H), 2.51-2.42 (m, 1H), 2.29-2.24 (m, 1H), 2.19 (s, 3H), 2.08 (s, 3H), 2.01 (s, 3H), 1.90-1.84 (m, 1H), 1.48 (s, 3H); HR-MS: $442.1539(\mathrm{M}+\mathrm{H})^{+}$, calculated, 442.1539.

6-(benzyloxy)-2,5,7,8-tetramethyl-N'-(2-oxoindolin-3ylidene)-3,4-dihydro-2H-chromene-2-carbohydrazide (6I) Yield: Light Yellow solid (74\%), MP: $258^{\circ} \mathrm{C}$; IR ( $\mathrm{KBr}$, $\left.\mathrm{v}, \mathrm{cm}^{-1}\right): 3,186(\mathrm{NH}), 1,679(\mathrm{CO}) ;{ }^{1} \mathrm{H}-\mathrm{NMR}(500 \mathrm{MHz}$, DMSO-d $\left.{ }_{6}, \mathrm{ppm}\right): 11.20(\mathrm{~s}, 1 \mathrm{H},-\mathrm{NH}), 7.50$ (d, J=8.0 Hz, 1H), 7.43 (d, J=7.3 Hz, 2H), 7.36 (t, $J=7.3 \mathrm{~Hz}, 2 \mathrm{H}), 7.33-7.30$ (m, 2H), $7.04(\mathrm{t}, J=7.3 \mathrm{~Hz}, 1 \mathrm{H}), 6.87$ (d, J=8.0 Hz, 1H), 4.60 (s, 2H), 2.65-2.60 (m, 1H), 2.54-2.47 (m, 1H), 2.30-2.26 (m, 1H), $2.22(\mathrm{~s}, 3 \mathrm{H}), 2.13(\mathrm{~s}, 3 \mathrm{H}), 2.06(\mathrm{~s}, 3 \mathrm{H}), 1.92-1.86$ $(\mathrm{m}, 1 \mathrm{H}), 1.49(\mathrm{~s}, 3 \mathrm{H}) ;{ }^{13} \mathrm{C}-\mathrm{NMR}\left(125 \mathrm{MHz}, \mathrm{DMSO}_{-}\right)$ $12.3\left(-\mathrm{CH}_{3}\right), 12.5\left(-\mathrm{CH}_{3}\right), 13.2\left(-\mathrm{CH}_{3}\right), 20.3\left(-\mathrm{CH}_{2}\right), 24.5$ $\left(-\mathrm{CH}_{3}\right), 29.4\left(-\mathrm{CH}_{2}\right), 74.6\left(-\mathrm{CH}_{2}\right), 78.5(>\mathrm{CH}<), 111.6$, $118.1,120.3,121.5,123.2,126.4,128.3,128.9,132.4,138.1$, 139.2, 143.1, 146.6, 149.3, $163.0(>\mathrm{C}=\mathrm{O}), 171.7(>\mathrm{C}=\mathrm{O})$; HR-MS: $484.2235(\mathrm{M}+\mathrm{H})^{+}$, calculated, 484.2236.
6-(benzyloxy)-2,5,7,8-tetramethyl-N'-( I-methyl-2oxoindolin-3-ylidene)-3,4-dihydro-2H-chromene-2carbohydrazide $(6 \mathrm{~m})$

Yield: Yellow-orange solid (92\%), MP: $170^{\circ} \mathrm{C}$; IR $\left(\mathrm{KBr}, \mathrm{v}, \mathrm{cm}^{-1}\right)$ : 3,236 (NH), 1,696 (CO); ${ }^{1} \mathrm{H}-\mathrm{NMR}\left(500 \mathrm{MHz}, \mathrm{CDCl}_{3}\right.$, ppm): 7.77 (d, $J=7.3 \mathrm{~Hz}, 1 \mathrm{H}), 7.47$ (d, $J=6.8 \mathrm{~Hz}, 2 \mathrm{H}), 7.39-7.36$ (m, 2H), 7.35-7.30 (m, 2H), 7.10 (t, $J=7.3 \mathrm{~Hz}, 1 \mathrm{H}), 6.82$ (d, $J=8.0$ $H z, 1 \mathrm{H}), 4.68$ (s, 2H), 3.23 (s, 3H), 2.70-2.62 (m, 2H), 2.53-2.49 (m, 1H), 2.37 (s, 3H), 2.25 (s, 3H), 2.13 (s, 3H), 2.03-1.99 (m, 1H); ${ }^{13} \mathrm{C}-\mathrm{NMR}\left(125 \mathrm{MHz}, \mathrm{CHCl}_{3}\right) 12.1\left(-\mathrm{CH}_{3}\right), 12.2$ $\left(-\mathrm{CH}_{3}\right), 13.0\left(-\mathrm{CH}_{3}\right), 20.4\left(-\mathrm{CH}_{2}\right), 24.6\left(-\mathrm{CH}_{3}\right), 25.7\left(>\mathrm{N}-\mathrm{CH}_{3}\right)$, $29.5\left(-\mathrm{CH}_{2}\right), 74.7\left(-\mathrm{CH}_{2}\right), 78.5(>\mathrm{C}<), 108.8,117.9,119.6$, $112.0,123.4,123.7,126.3,127.7,127.9,128.5,128.6,131.7$ $137.9,138.2,143.8,146.6,149.3,161.0(>\mathrm{C}=\mathrm{O}), 172.9$ $(>\mathrm{C}=\mathrm{O})$; HR-MS: $498.2399(\mathrm{M}+\mathrm{H})^{+}$, calculated, 498.2392.

6-(benzyloxy)-N'-(5-bromo-2-oxoindolin-3-ylidene)2,5,7,8-tetramethyl-3,4-dihydro-2H-chromene-2carbohydrazide (6n)

Yield: Yellow solid (68\%), MP: $270^{\circ} \mathrm{C}$; IR ( $\left.\mathrm{KBr}, \mathrm{v}, \mathrm{cm}^{-1}\right): 3,189$ (NH), 1,677 (CO); ${ }^{1} \mathrm{H}-\mathrm{NMR}$ (500 MHz, DMSO-d, ppm): 11.32 (s, 1H, -NH), 7.57 (s, 1H), 7.50 (d, J=8.2 Hz, 1H), 7.43 (d, J=7.3 Hz, 2H), 7.37 (t, J=7.3 Hz, 2H), 7.33-7.30 (m, 1H), $6.84(\mathrm{~d}, J=8.2 \mathrm{~Hz}, 1 \mathrm{H}), 4.59$ (s, 2H), 2.66-2.58 (m, 1H), 2.54 $2.44(\mathrm{~m}, 1 \mathrm{H}), 2.32-2.25(\mathrm{~m}, 1 \mathrm{H}), 2.22(\mathrm{~s}, 3 \mathrm{H}), 2.13(\mathrm{~s}, 3 \mathrm{H}), 2.06$ (s, 3H), 1.94-1.86 (m, 1H), $1.50(\mathrm{~s}, 3 \mathrm{H}) ;{ }^{13} \mathrm{C}-\mathrm{NMR}(125 \mathrm{MHz}$, DMSO-d $)_{6}: 12.2\left(-\mathrm{CH}_{3}\right), 12.4\left(-\mathrm{CH}_{3}\right), 13.2\left(-\mathrm{CH}_{3}\right), 20.2$ $\left(-\mathrm{CH}_{2}\right), 24.4\left(-\mathrm{CH}_{3}\right), 29.3\left(-\mathrm{CH}_{2}\right), 74.6\left(-\mathrm{CH}_{2}\right), 78.5(>\mathrm{C}<)$, 113.6, 118.1, 121.5, 123.1, 123.7, 126.4, 128.3, 128.9, 135.0, 138.2, 142.2, 146.5, 149.3, $162.7(>\mathrm{C}=\mathrm{O}), 171.7(>\mathrm{C}=\mathrm{O})$; HR-MS: $562.1349(\mathrm{M}+\mathrm{H})^{+}$, calculated, 562.1341.

6-(benzyloxy)-N'-(5-fluoro-2-oxoindolin-3-ylidene)2,5,7,8-tetramethyl-3,4-dihydro-2H-chromene-2carbohydrazide (6o)

Yield: Yellow solid (85\%), MP: $>300^{\circ} \mathrm{C}$; IR $\left(\mathrm{KBr}, \mathrm{v}, \mathrm{cm}^{-1}\right)$ : 3,195 (NH), 1,681 (CO); ' H-NMR (500 MHz, DMSO-d, ppm): 11.21 (s, 1H, -NH), 7.43 (d, J=7.4 Hz, 2H), 7.37 (t, $J=7.0 \mathrm{~Hz}, 2 \mathrm{H}), 7.31-7.30(\mathrm{~m}, 2 \mathrm{H}), 7.18(\mathrm{t}, J=9.0 \mathrm{~Hz}, 1 \mathrm{H})$, $6.87(\mathrm{dd}, J=4,8.6 \mathrm{~Hz}, 1 \mathrm{H}), 4.59$ (s, 2H), 2.65-2.60 (m, 1H), 2.53-2.47 (m, 1H), 2.31-2.25 (m, 1H), 2.22 (s, 3H), $2.12(\mathrm{~s}$, $3 \mathrm{H}), 2.06(\mathrm{~s}, 3 \mathrm{H}), 1.92-1.87$ (m, 1H), 1.50 (s, 3H); HR-MS: $502.2146(\mathrm{M}+\mathrm{H})^{+}$, calculated, 502.2142.

6-(benzyloxy)-N'-(5-chloro- I-methyl-2-oxoindolin-3ylidene)-2,5,7,8-tetramethyl-3,4-dihydro-2H-chromene-2carbohydrazide (6p)

Yield: Dark Yellow solid (81\%), MP: $220^{\circ} \mathrm{C}$; IR (KBr, $\mathrm{v}, \mathrm{cm}^{-1}$ ): 3,260 (NH), 1,712 (CO); ${ }^{1} \mathrm{H}-\mathrm{NMR}(500 \mathrm{MHz}$, 
DMSO-d $\left.{ }_{6}, \mathrm{ppm}\right):$ 7.49-7.46 (m, 2H), 7.44-7.43 (m, 2H), 7.37 $(\mathrm{t}, J=7.3 \mathrm{~Hz}, 2 \mathrm{H}), 7.33-7.29(\mathrm{~m}, 1 \mathrm{H}), 7.12(\mathrm{~d}, J=8.5 \mathrm{~Hz}, 1 \mathrm{H})$, 4.59 (s, 2H), 3.14 (s, 3H), 2.65-2.60 (m, 1H), 2.54-2.47 (m, 1H), 2.30-2.25 (m, 1H), 2.24 (s, 3H), 2.13 (s, 3H), 2.06 (s, 3H), 1.93-1.89 (m, 1H), 1.50 (s, 3H); HR-MS: 532.1992 $(\mathrm{M}+\mathrm{H})^{+}$, calculated, 532.2003.

\section{6-(benzyloxy)-N'-(5-chloro-2-oxoindolin-3-ylidene)-} 2,5,7,8-tetramethyl-3,4-dihydro-2H-chromene-2-

\section{carbohydrazide (6q)}

Yield: Yellow solid (94\%), MP: $280^{\circ} \mathrm{C}$; IR (KBr, v, cm $\left.{ }^{-1}\right)$ : 3,188 (NH), 1,678 (CO); ${ }^{1} \mathrm{H}-\mathrm{NMR}$ (500 MHz, DMSO-d ${ }_{6}$, ppm): 11.31 (s, 1H, -NH), 7.46 (d, $J=2.5 \mathrm{~Hz}, 1 \mathrm{H}), 7.44-7.42$ $(\mathrm{m}, 2 \mathrm{H}), 7.38-7.35(\mathrm{~m}, 3 \mathrm{H}), 7.32-7.29(\mathrm{~m}, 1 \mathrm{H}), 6.89$ (d, $J=8.0 ~ H z, 1 \mathrm{H}), 4.60(\mathrm{~s}, 2 \mathrm{H}), 2.66-2.60(\mathrm{~m}, 1 \mathrm{H}), 2.53-2.47$ (m, 1H), 2.31-2.27 (m, 1H), 2.21 (s, 3H), 2.12 (s, 3H), 2.06 (s, 3H), 1.92-1.87 (m, 1H), 1.50 (s, 3H); HR-MS: 516.1685 $(\mathrm{M}-\mathrm{H})^{-}$, calculated, 516.1690.

\section{In vitro anticancer activity determination by sulforhodamine B assay}

The anticancer activity was measured in vitro in the human breast cancer cell line (MCF-7) using sulforhodamine B stain assay applying the method of Skehan et al. ${ }^{23}$ Human breast cancer cell line MCF-7 was obtained from the Advanced Centre for Treatment Research and Education in Cancer (ACTREC), Navi Mumbai, Maharashtra, India, and were grown in RPMI-1640 medium supplemented with 10\% heatinactivated fetal calf serum, $100 \mu \mathrm{g} / \mathrm{mL}$ streptomycin, and $100 \mathrm{U} / \mathrm{mL}$ penicillin at $37^{\circ} \mathrm{C}$ in a humidified atmosphere with $5 \% \mathrm{CO}_{2}$. All compounds $(6 \mathrm{a}-\mathrm{q})$ were dissolved in DMSO to give a stock solution of $10 \mu \mathrm{g} / \mathrm{mL}$, from which further dilutions $\left(10^{-7} \mathrm{M}, 10^{-6} \mathrm{M}, 10^{-5} \mathrm{M}\right.$, and $\left.10^{-4} \mathrm{M}\right)$ in culture medium were prepared. Control cultures were treated with DMSO alone. Cells were plated in 96-well plates $\left(10^{4}\right.$ cells per well) for 24 hours before treatment with the compounds. Different concentrations of the test compounds $\left(10^{-7} \mathrm{M}\right.$, $10^{-6} \mathrm{M}, 10^{-5} \mathrm{M}$, and $10^{-4} \mathrm{M}$ ) were added to the cell monolayer. Triplicate wells were prepared for each individual dose. Monolayer cells were then incubated with test compounds for 48 hours at $37^{\circ} \mathrm{C}$ in an atmosphere of $5 \% \mathrm{CO}_{2}$. After 48 hours, cells were fixed, washed, and stained with sulforhodamine B stain. Excess stain was washed with acetic acid and the attached stain was recovered with Tris-EDTA buffer. Color intensity was measured using an enzyme-linked immunosorbent assay reader. The relation between surviving fraction and drug concentration was plotted and the $\mathrm{GI}_{50}$ was calculated for each compound.

\section{Antiepileptic activity}

The synthesized compounds $(6 a-q)$ obtained from the reaction sequence were dissolved in polyethyleneglycol (PEG400) administered intraperitoneally into male albino mice (CF-1 strain, 18-25 g) and tested in the MES, ${ }^{24} \mathrm{PTZ}$ seizure, ${ }^{25}$ and neurotoxicity screens, ${ }^{26}$ using $30 \mathrm{mg} / \mathrm{kg}, 100 \mathrm{mg} / \mathrm{kg}$, and $300 \mathrm{mg} / \mathrm{kg}$ doses; and observations were recorded at two different time intervals. All experimental protocols were carried out with permission from the Institutional Animal Ethics Committee (IAEC), Birla Institute of Technology, Mesra, Ranchi (CPCSEA approval no: BIT/PH/IAEC/13/2014, dated April 30, 2014), and the experiments were in compliance with the animal care guidelines issued by the IAEC.

\section{The MES test}

Albino mice were divided into groups of six animals each. Maximal seizures were induced by the application of alternating current of $60 \mathrm{~Hz}(50 \mathrm{~mA})$ for 0.2 seconds using corneal electrodes primed with an electrolyte solution containing an anesthetic agent $(0.5 \%$ tetracaine $\mathrm{HCl})$. During the preliminary screening, the test compounds were administered by intraperitoneal injection at $0.01 \mathrm{~mL} / \mathrm{kg}$ body weight at doses of $30 \mathrm{mg} / \mathrm{kg}$, $100 \mathrm{mg} / \mathrm{kg}$, and $300 \mathrm{mg} / \mathrm{kg}$ prior to testing, and anticonvulsant activity was evaluated after 0.5 hours and 4 hours of administration. Abolition of the hind limb tonic extensor spasm was recorded as anticonvulsant activity in the MES method. ${ }^{27}$

\section{The PTZ seizure test}

The synthesized compounds were administered to mice $(n=6)$ by intraperitoneal injection. After 30 minutes, mice were treated with a subcutaneous injection of PTZ $(60 \mathrm{mg} / \mathrm{kg})$. Then, the mice were placed singly in isolated plastic cages and observed for 60 minutes. Protection was referred to as the failure to detect an episode of clonic spasms of at least 5 -second duration during this time period.

\section{Neurotoxicity screening}

Neurotoxicity was measured by the rotarod test. Mice $(n=6)$ were given intraperitoneal injection of the synthesized compounds at dose levels of $30 \mathrm{mg} / \mathrm{kg}, 100 \mathrm{mg} / \mathrm{kg}$, and $300 \mathrm{mg} / \mathrm{kg}$. Then, after 30 minutes, the mice were placed on the rotating rod. Neurotoxicity was determined by the inability of the mice to maintain equilibrium on the rod for 1 minute in each of the three trials. ${ }^{16}$

\section{Results and discussion Chemistry}

The chroman derivatives $(6 a-q)$ described in this study were prepared as depicted in Figure 2. The synthesis of 


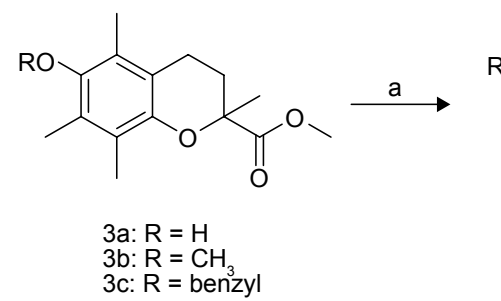<smiles>[R]c1c(C)c(C)c2c(c1C)OC(C)(C(=O)N[NH3+])CC2</smiles>

4a: $\mathrm{R}=\mathrm{H}$
$4 \mathrm{~b}: \mathrm{R}=\mathrm{CH}$

4c: $R=$ benzyl<smiles>[R]c1cccc2c1N([R])C(=O)C2=O</smiles>

3c: $R=$ benzyl

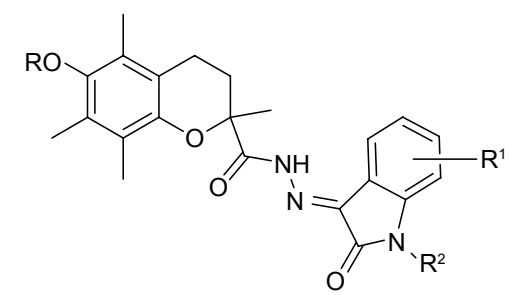

$6 a-q$

Figure 2 Synthesis pathway for compounds 6a-q.

Notes: Reactions a and b carried out under the following conditions: $\mathrm{NH}_{2} \mathrm{NH}_{2} \cdot \mathrm{H}_{2} \mathrm{O}, \mathrm{C}_{2} \mathrm{H}_{5} \mathrm{OH}$, reflux, 10 hours; $\mathrm{C}_{2} \mathrm{H}_{5} \mathrm{OH}, \mathrm{CH}_{3} \mathrm{COOH}$, reflux, 4-I2 hours.

6-substituted-2,5,7,8-tetramethyl-chroman-2-carboxylic acid methyl ester ( $3 \mathrm{a}-\mathrm{c})$ as a key intermediate was accomplished by the reaction of trimethylhydroquinone and methyl methacrylate to produce $3 \mathrm{a},{ }^{22}$ followed by methylation (yielding $3 b)^{28}$ and benzylation (to yield $3 \mathrm{c}$ ). ${ }^{11}$ The ester moieties of $3 \mathrm{a}-\mathrm{c}$ endured the nucleophilic attack by hydrazine hydrate, resulting in $4 \mathrm{a}-\mathrm{c} .{ }^{29}$ The latter compounds were subjected to condensation reaction with different substituted isatins to produce $6 \mathrm{a}-\mathrm{q}$ with $51 \%-94 \%$ yield. ${ }^{21}$ The properties of the synthesized compounds $6 \mathrm{a}-\mathrm{q}$ are shown in Table 1.
The compounds were characterized by Fourier transform infrared spectroscopy (FTIR), ${ }^{1} \mathrm{H}$-nuclear magnetic resonance (NMR), ${ }^{13} \mathrm{C}-\mathrm{NMR}$, mass spectroscopy, and melting point analysis. The analytical data were fully consistent with the proposed structures. The retention factor (Rf) value of all synthesized compounds $(6 a-q)$ was calculated in ethyl acetate (EtOAc) and hexane (40:60) and ranged between 0.4 and 0.7 .

In the FTIR spectrum, bands at $3,284-3,598 \mathrm{~cm}^{-1}$ and $1,600-1,700 \mathrm{~cm}^{-1}$ confirm the presence of $-\mathrm{NH}$ and $-\mathrm{CO}$

Table I Some properties of the compounds $6 a-q$

\begin{tabular}{|c|c|c|c|c|c|c|c|c|c|}
\hline Compound ${ }^{\mathrm{a}, \mathrm{b}}$ & $\mathbf{R}$ & $\mathbf{R}^{\prime}$ & $\mathbf{R}^{2}$ & $\begin{array}{l}\text { Time } \\
\text { (hours) }\end{array}$ & $\begin{array}{l}\text { Yield } \\
(\%)^{c}\end{array}$ & $\begin{array}{l}\text { Melting } \\
\text { point }\left({ }^{\circ} \mathrm{C}\right)\end{array}$ & $\begin{array}{l}\text { Molecular } \\
\text { formula }\end{array}$ & $\begin{array}{l}\text { Molecular } \\
\text { weight }\end{array}$ & $\mathbf{R f}^{\mathrm{d}}$ \\
\hline $6 a$ & $\mathrm{H}$ & $\mathrm{H}$ & $\mathrm{H}$ & 4 & 74 & 240 & $\mathrm{C}_{22} \mathrm{H}_{23} \mathrm{~N}_{3} \mathrm{O}_{4}$ & 393.44 & 0.7 \\
\hline $6 b$ & $\mathrm{H}$ & $\mathrm{H}$ & $\mathrm{CH}_{3}$ & 6 & 72 & 237 & $\mathrm{C}_{23} \mathrm{H}_{25} \mathrm{~N}_{3} \mathrm{O}_{4}$ & 407.46 & 0.7 \\
\hline $6 c$ & $\mathrm{H}$ & $5-\mathrm{Cl}$ & $\mathrm{H}$ & 6 & 87 & 255 & $\mathrm{C}_{22} \mathrm{H}_{22} \mathrm{~N}_{3} \mathrm{O}_{4} \mathrm{Cl}$ & 427.88 & 0.6 \\
\hline $6 d$ & $\mathrm{H}$ & $5-\mathrm{Br}$ & $\mathrm{H}$ & 6 & 56 & 260 & $\mathrm{C}_{22} \mathrm{H}_{22} \mathrm{~N}_{3} \mathrm{O}_{4} \mathrm{Br}$ & 472.33 & 0.4 \\
\hline $6 e$ & $\mathrm{H}$ & $6-\mathrm{Cl}$ & $\mathrm{H}$ & 5 & 57 & 290 & $\mathrm{C}_{22} \mathrm{H}_{22} \mathrm{~N}_{3} \mathrm{O}_{4} \mathrm{Cl}$ & 427.88 & 0.5 \\
\hline $6 f$ & $\mathrm{H}$ & $5-F$ & $\mathrm{H}$ & 4 & 51 & 290 & $\mathrm{C}_{22} \mathrm{H}_{22} \mathrm{~N}_{3} \mathrm{O}_{4} \mathrm{~F}$ & 411.43 & 0.4 \\
\hline $6 g$ & $\mathrm{H}$ & $5-\mathrm{Cl}$ & $\mathrm{CH}_{3}$ & 5 & 59 & 257 & $\mathrm{C}_{23} \mathrm{H}_{24} \mathrm{~N}_{3} \mathrm{O}_{4} \mathrm{Cl}$ & 441.91 & 0.5 \\
\hline $6 \mathrm{~h}$ & $\mathrm{CH}_{3}$ & $\mathrm{H}$ & $\mathrm{H}$ & 3 & 58 & 256 & $\mathrm{C}_{23} \mathrm{H}_{25} \mathrm{~N}_{3} \mathrm{O}_{4}$ & 407.46 & 0.6 \\
\hline $6 i$ & $\mathrm{CH}_{3}$ & $5-\mathrm{Br}$ & $\mathrm{H}$ & 5 & 51 & 290 & $\mathrm{C}_{23} \mathrm{H}_{24} \mathrm{~N}_{3} \mathrm{O}_{4} \mathrm{Br}$ & 486.36 & 0.6 \\
\hline $6 j$ & $\mathrm{CH}_{3}$ & $5-F$ & $\mathrm{H}$ & 5 & 66 & $<300$ & $\mathrm{C}_{23} \mathrm{H}_{24} \mathrm{~N}_{3} \mathrm{O}_{4} \mathrm{~F}$ & 425.45 & 0.5 \\
\hline $6 k$ & $\mathrm{CH}_{3}$ & $6-\mathrm{Cl}$ & $\mathrm{H}$ & 5 & 52 & 270 & $\mathrm{C}_{23} \mathrm{H}_{24} \mathrm{~N}_{3} \mathrm{O}_{4} \mathrm{Cl}$ & 441.91 & 0.5 \\
\hline 61 & $\mathrm{C}_{6} \mathrm{H}_{5}$ & $\mathrm{H}$ & $\mathrm{H}$ & 12 & 74 & 258 & $\mathrm{C}_{29} \mathrm{H}_{29} \mathrm{~N}_{3} \mathrm{O}_{4}$ & 483.56 & 0.7 \\
\hline $6 \mathrm{~m}$ & $\mathrm{C}_{6} \mathrm{H}_{5}$ & $\mathrm{H}$ & $\mathrm{CH}_{3}$ & 12 & 92 & 170 & $\mathrm{C}_{31} \mathrm{H}_{33} \mathrm{~N}_{3} \mathrm{O}_{4}$ & 511.61 & 0.6 \\
\hline $6 n$ & $\mathrm{C}_{6} \mathrm{H}_{5}$ & $5-\mathrm{Br}$ & $\mathrm{H}$ & 12 & 68 & 270 & $\mathrm{C}_{29} \mathrm{H}_{28} \mathrm{~N}_{3} \mathrm{O}_{4} \mathrm{Br}$ & 562.45 & 0.6 \\
\hline 60 & $\mathrm{C}_{6} \mathrm{H}_{5}$ & $5-\mathrm{F}$ & $\mathrm{H}$ & 12 & 85 & $<300$ & $\mathrm{C}_{29} \mathrm{H}_{28} \mathrm{~N}_{3} \mathrm{O}_{4} \mathrm{~F}$ & 501.55 & 0.6 \\
\hline $6 p$ & $\mathrm{C}_{6} \mathrm{H}_{5}$ & $5-\mathrm{Cl}$ & $\mathrm{CH}_{3}$ & 12 & 81 & 220 & $\mathrm{C}_{30} \mathrm{H}_{30} \mathrm{~N}_{3} \mathrm{O}_{4} \mathrm{Cl}$ & 532.03 & 0.7 \\
\hline $6 q$ & $\mathrm{C}_{6} \mathrm{H}_{5}$ & $5-\mathrm{Cl}$ & $\mathrm{H}$ & 12 & 94 & 280 & $\mathrm{C}_{29} \mathrm{H}_{28} \mathrm{~N}_{3} \mathrm{O}_{4} \mathrm{Cl}$ & 518.00 & 0.6 \\
\hline
\end{tabular}

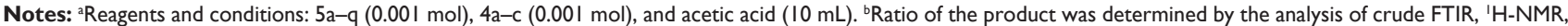
${ }^{13} \mathrm{C}-\mathrm{NMR}$, and mass spectra. ${ }^{\mathrm{C} Y i e l d}$ refers to pure products after recrystallization. ${ }^{\mathrm{d}} \mathrm{Rf}$ studied in EtOAc/hexane $(40: 60)$. $R=$ hydrogen, methyl, and benzyl; $\mathrm{R}^{\prime}=$ hydrogen and halogen; and $\mathrm{R}^{2}=$ hydrogen and methyl.

Abbreviations: EtOAc, ethyl acetate; FTIR, Fourier transform infrared spectroscopy; NMR, nuclear magnetic resonance; Rf, retention factor. 
Table 2 Anti-breast cancer and antiepileptic activities of the compounds $6 \mathrm{a}-\mathrm{q}$

\begin{tabular}{|c|c|c|c|c|c|}
\hline \multirow[t]{2}{*}{ Compound } & \multirow[t]{2}{*}{$\mathbf{G I}_{50}(\mu \mathbf{M})^{a}$} & \multicolumn{2}{|l|}{ MES } & \multicolumn{2}{|l|}{$\mathbf{P T Z}^{\mathrm{b}}$} \\
\hline & & 0.5 hours & 4 hours & 0.5 hours & 4 hours \\
\hline $6 a$ & 37.1 & - & - & 300 & 300 \\
\hline $6 b$ & $>100$ & 30 & 30 & 100 & 100 \\
\hline $6 c$ & 76.4 & 30 & 30 & 100 & 300 \\
\hline $6 d$ & 57.3 & - & - & 30 & 30 \\
\hline $6 e$ & 46.9 & 100 & 300 & 30 & 30 \\
\hline $6 f$ & 62.7 & - & - & 300 & 300 \\
\hline $6 g$ & $>100$ & 30 & 30 & 100 & 100 \\
\hline $6 \mathrm{~h}$ & 45.1 & 300 & 300 & 100 & 100 \\
\hline $6 i$ & 34.7 & - & - & 30 & 100 \\
\hline $6 j$ & $>100$ & 100 & 100 & 100 & 300 \\
\hline $6 \mathrm{k}$ & 38.2 & 100 & 300 & 100 & 100 \\
\hline 61 & 45.9 & - & - & 30 & 30 \\
\hline $6 \mathrm{~m}$ & $>100$ & 100 & 100 & 100 & 100 \\
\hline $6 n$ & 76.6 & - & - & 100 & 100 \\
\hline 60 & 64.1 & 300 & 300 & 300 & 300 \\
\hline $6 p$ & 77.9 & 100 & 100 & 100 & 100 \\
\hline $6 q$ & $>100$ & 100 & 100 & 100 & 100 \\
\hline Adriamycin & $<0.1$ & & & & \\
\hline Phenytoin & & 30 & 30 & & \\
\hline Sodium & & & & 200 & 200 \\
\hline
\end{tabular}

Notes: ${ }^{\mathrm{a}} \mathrm{GI}_{50}$ is the concentration of drug causing $50 \%$ inhibition of cell growth. 'Doses of $30 \mathrm{mg} / \mathrm{kg}, 100 \mathrm{mg} / \mathrm{kg}$, and $300 \mathrm{mg} / \mathrm{kg}$ were administered. The figure in the table indicates the minimum dose required for bioactivity in half or more of the mice examined at 0.5 hours and 4 hours. Dash indicates the absence of anticonvulsant activity and neurotoxicity at the maximum dose administered $(300 \mathrm{mg} / \mathrm{kg})$. Abbreviations: MES, maximal electroshock seizure; PTZ, pentylenetetrazole.

stretching vibrations, respectively. Compounds $6 \mathrm{a}-\mathrm{g}$ showed broad absorption bands at 3,141-3,406 $\mathrm{cm}^{-1}$, indicative of a hydroxy group (-OH stretch). The ${ }^{1} \mathrm{H}-\mathrm{NMR}$ spectrum revealed a singlet at $\delta=11.19-11.32 \mathrm{ppm}$ due to $\mathrm{NH}_{2}$ protons $\left(-\mathrm{CONH}_{2}\right)$. The presence of a hydroxy group $(-\mathrm{OH})$ in the compounds $6 \mathrm{a}-\mathrm{g}$ was confirmed by the sharp singlet at $\delta=7.52-7.55 \mathrm{ppm}$. The methoxy group $\left(-\mathrm{OCH}_{3}\right)$ showed a singlet at $\delta=3.48-3.49$ ppm in compounds $6 \mathrm{~h}-\mathrm{k}$. Compounds 61-q displayed a singlet peak at $\delta=4.59-4.67$ ppm, corresponding to benzylic methyl $\left(-\mathrm{CH}_{2}-\right)$. In ${ }^{13} \mathrm{C}-\mathrm{NMR}$, the carbonyl group of amide $(\mathrm{C}=\mathrm{O})$ was observed at approximately $\delta=160-172$ ppm. The mass spectra showed $(\mathrm{M}+\mathrm{H})^{+}$ and $\left(\mathrm{M}+\mathrm{Na}^{+}\right)^{+}(\mathrm{m} / \mathrm{z})$ peaks, respectively confirming their purity and molecular weight.

\section{In vitro anticancer activity screening}

The synthesized compounds (6a-q) were screened for in vitro anticancer activity against human mammary adenocarcinoma (MCF-7) by using sulforhodamine B assay. ${ }^{23}$ The concentration required for $50 \%$ inhibition of cell growth $\left(\mathrm{GI}_{50}\right)$ for each compound was calculated with reference to a control sample.
For each compound, $\mathrm{GI}_{50}$ was calculated from the sigmoidal dose-response curves and the values are presented in Table 2. The data for adriamycin are included as reference.

The resultant data showed that the chroman derivatives (6a-q) produced significant cytostatic effects against the human breast cancer MCF-7 cell line. The results revealed that compound $6 \mathrm{i}$ was the most active member of the series, with $\mathrm{GI}_{50}=34.7 \mu \mathrm{M}$. Among all the compounds, compounds $6 \mathrm{a}, 6 \mathrm{i}$, and $6 \mathrm{k}$ showed promising activity, with $\mathrm{GI}_{50}$ values of $37.1 \mu \mathrm{M}, 34.7 \mu \mathrm{M}$, and $38.2 \mu \mathrm{M}$, respectively; compounds $6 \mathrm{~d}, 6 \mathrm{e}, 6 \mathrm{~h}$, and 61 showed $\mathrm{GI}_{50}$ values of $57.3 \mu \mathrm{M}$, $46.9 \mu \mathrm{M}, 45.1 \mu \mathrm{M}$, and $45.9 \mu \mathrm{M}$, respectively; compounds $6 \mathrm{c}, 6 \mathrm{f}, 6 \mathrm{n}, 6 \mathrm{o}$, and $6 \mathrm{p}$ showed $\mathrm{GI}_{50}$ values of $76.4 \mu \mathrm{M}$, $62.7 \mu \mathrm{M}, 76.6 \mu \mathrm{M}, 64.1 \mu \mathrm{M}$, and $77.9 \mu \mathrm{M}$, respectively; the remaining five compounds $6 \mathrm{~b}, 6 \mathrm{~g}, 6 \mathrm{j}, 6 \mathrm{~m}$, and $6 \mathrm{q}$ showed $\mathrm{GI}_{50}$ values $>100 \mu \mathrm{M}$ in the MCF-7 breast cancer cells. The activity was attributed to the presence of chlorine or bromine group at the fifth position on the phenyl ring of the isatin ring system, whereas in the presence of fluorine, the phenyl group of the isatin ring system induced reduced activity. However, the chlorine group at the sixth position accounts for more activity than the chlorine group at the fifth position. Benzyl substitution in the chroman ring system appeared to be less active than methoxy and hydroxyl substitution.

\section{Antiepileptic activity}

The antiepileptic activity and the acute neurotoxicity of all synthesized compounds $(6 a-q)$ were evaluated by the use of standard techniques. ${ }^{24-26}$ Results are presented in Table 2. Phenytoin and carbamazepine were used as the standard drugs for the comparisons.

The most potent compounds $6 \mathrm{~b}, 6 \mathrm{c}$, and $6 \mathrm{~g}$ resembled the standard drug phenytoin at the dose level of $30 \mathrm{mg} / \mathrm{kg}$ after 0.5 hours and 4 hours by the maximal electroshock seizure (MES) method. On the other hand, compounds $6 \mathrm{j}, 6 \mathrm{~m}, 6 \mathrm{p}$, and $6 \mathrm{q}$ displayed activity at the dose level of $100 \mathrm{mg} / \mathrm{kg}$ against seizure spread at both the time intervals, whereas compounds $6 \mathrm{e}$ and $6 \mathrm{k}$ displayed protection at the dose level of $300 \mathrm{mg} / \mathrm{kg}$ after 4 hours, suggesting rapid onset but shorter duration of action. Compounds $6 \mathrm{~h}$ and 60 exhibited protection at both the time intervals 0.5 hours and 4 hours after the dose level of $300 \mathrm{mg} / \mathrm{kg}$.

In the pentylenetetrazole (PTZ) screen, the most active of these compounds were $6 \mathrm{~d}, 6 \mathrm{e}$, and 61 , which provided protection at the dose level of $30 \mathrm{mg} / \mathrm{kg}$ after both the time intervals 0.5 hours and 4 hours, excluding compound 6i, which showed protection at the $100 \mathrm{mg} / \mathrm{kg}$ dose level after 4 hours. Compounds $6 \mathrm{~b}, 6 \mathrm{~g}, 6 \mathrm{~h}, 6 \mathrm{k}, 6 \mathrm{~m}, 6 \mathrm{n}, 6 \mathrm{p}$, and $6 \mathrm{q}$ exhibited protection 
at the $100 \mathrm{mg} / \mathrm{kg}$ dose level after both time intervals, whereas compounds $6 \mathrm{c}$ and $6 \mathrm{j}$ showed protection at $100 \mathrm{mg} / \mathrm{kg}$ after 4 hours. The remaining compounds had activity at the dose level of $300 \mathrm{mg} / \mathrm{kg}$ at both the time intervals.

Compounds that afforded protection against seizures in the MES and PTZ screens were further tested for their neurotoxicity. All compounds (6a-q) were devoid of neurotoxicity, as determined by the rotarod test.

Gamma-aminobutyric acid (GABA) is the principal inhibitory neurotransmitter substance in the brain and it is widely implicated in epilepsy. It has been reported that PTZ produces seizures by inhibiting GABA neurotransmission. In order to inhibit seizures, enhancement of GABAergic neurotransmission is useful. All newly synthesized compounds (6a-q) showed protection against seizure in the PTZ model (Table 2). These findings suggest that the compounds may have inhibited or attenuated PTZ-induced seizure in mice by enhancing GABAergic neurotransmission. ${ }^{30}$

The antiepileptic activity correlation of the synthesized compounds $(6 \mathrm{a}-\mathrm{q})$ revealed that compounds containing a hydroxyl group in the chroman ring system, such as $6 \mathrm{~b}$, $6 \mathrm{c}, 6 \mathrm{~d}, 6 \mathrm{e}$, and $6 \mathrm{~g}$, were more potent as compared to the compounds containing a methyl group (6h, $6 \mathrm{i}$, and 6k). Compounds having a benzyl group, such as $61,6 \mathrm{n}$, and 60 , in the chroman ring system were the least active. The presence of electron-withdrawing substituents $(\mathrm{Cl}, \mathrm{Br}$, and $\mathrm{F})$ in the isatin ring system might have increased the activity, as compounds $6 \mathrm{c}, 6 \mathrm{~g}, 6 \mathrm{j}, 6 \mathrm{~m}$, and $6 \mathrm{q}$ were more active than compounds $6 \mathrm{a}, 6 \mathrm{~h}$, and 61 . However, compounds, such as $6 \mathrm{f}, 6 \mathrm{j}$, and 60 , which have a fluorine substituent, were found to be less active than compounds with the other electron-withdrawing substituents ( $\mathrm{Cl}$ and $\mathrm{Br})$.

\section{Conclusion}

In this study, the design and synthesis of a series of chroman derivatives have been described. All synthesized compounds were evaluated for their anti-breast cancer and antiepileptic activities. The results of the study demonstrated that compound $6 \mathrm{i}$ exerted the most potent activity $\left(\mathrm{GI}_{50}=34.7 \mu \mathrm{M}\right)$ among the compounds in the series. Additionally, all synthesized compounds were evaluated for their antiepileptic efficacy. In the antiepileptic evaluation, compounds $6 \mathrm{~b}-\mathrm{e}$, $6 \mathrm{~g}, 6 \mathrm{i}$, and 61 were found to be more active than the reference drugs. This work adds new data to the relationship between chromans and their anti-breast cancer and antiepileptic activities. This provides a platform for further development of related compounds into more active compounds.

\section{Acknowledgments}

The authors thank the Advanced Centre for Treatment Research and Education in Cancer (ACTREC), Navi Mumbai, Maharashtra, India, for evaluation of the in vitro anticancer activity. Ms Pinki Rawat is thankful to University Grants Commission - Rajiv Gandhi National Fellowship for providing financial support in the form of National Doctoral Fellowship.

\section{Disclosure}

The authors report no conflicts of interest in this work.

\section{References}

1. Viswas KC, Solomon R, Lee H, Trivedi P. Design, synthesis and biological evaluation of some isatin-linked chalcones as novel anti-breast cancer agents: a molecular hybridization approach. Biomed Prev Nutr. 2013;3(4):325-330.

2. Koufaki M, Kiziridi C, Alexi X, Alexis MN. Design and synthesis of novel neuroprotective 1,2 dithiolane/chroman hybrids. Bioorg Med Chem. 2009;17(17):6432-6441.

3. Kanbe Y, Kim MH, Nishimoto M, et al. Discovery of thiochroman and chroman derivatives as pure antiestrogens and their structure-activity relationship. Bioorg Med Chem. 2006;14(14):4803-4819.

4. Lee H, Lee K, Jung JK, Cho J, Theodorakis EA. Synthesis and evaluation of 6-hydroxy-7-methoxy-4-chromanone- and chroman-2-carboxamides as antioxidants. Bioorg Med Chem Lett. 2005;15(11):2745-2748.

5. Kraus GA, Mengwasser J, Maury W, Oh C. Synthesis of chroman aldehydes that inhibit HIV. Bioorg Med Chem Lett. 2011;21(5):1399-1401.

6. Gupta A, Dwivedy A, Keshri G, et al. Rapid synthesis of 4-benzylidene and 4-[bis-(4-methoxyphenyl)-methylene-2-substituted phenyl-benzopyrans as potential selective estrogen receptor modulators (SERMs) using McMurry coupling reaction. Bioorg Med Chem Lett. 2006; 16(23):6006-6012.

7. Reddy BVS, Divya B, Swaina M, Rao TP, Yadav JS, Vishnu Vardhan MV. A domino Knoevenagel hetero-Diels-Alder reaction for the synthesis of polycyclic chromene derivatives and evaluation of their cytotoxicity. Bioorg Med Chem Lett. 2012;22(5):1995-1999.

8. Wang D, Chuang HC, Weng SC, et al. $\alpha$-Tocopheryl succinate as a scaffold to develop potent inhibitors of breast cancer cell adhesion. J Med Chem. 2009;52(18):5642-5648.

9. Lal J. Clinical pharmacokinetics and interaction of centchroman - a mini review. Contraception. 2010;81(4):275-280.

10. Li X, Rebecca F, Xiaoke H, et al. Discovery of a novel drug KBU2046 that inhibits conversion of human prostate cancer to a metastatic phenotype. Cancer Prev Res. 2010;3:B58.

11. Chen CL, Levine A, Rao A, et al. Clinical pharmacokinetics of the CD19 receptor-directed tyrosine kinase inhibitor B43-genistein in patients with B-lineage lymphoid malignancies. J Clin Pharmacol. 1999; 39(12):1248-1255.

12. Kavitha P, Chary MR, Singavarapu BVVA, Reddy KL. Synthesis, characterization, biological activity and DNA cleavage studies of tridentate Schiff bases and their Co(II) complexes. J Saudi Chem Soc. 2016;20(1): 69-80.

13. Collins I, Jones AM. Diversity-oriented synthetic strategies applied to cancer chemical biology and drug discovery. Molecules. 2014;19(11): 17221-17255.

14. Bell GS, Sander JW. The epidemiology of epilepsy: the size of the problem. Seizure. 2002;11(suppl A):306-314.

15. Bhat MA, Siddiqui N, Khan SA. Synthesis of novel 3-(4-acetyl-5h/ methyl-5-substitutedPhenyl-4,5-dihydro-1,3,4-oxadiazol-2-yl)-2hchromen-2-ones As potential anticonvulsant agents. Acta Pol Pharm. 2008;65(2):235-239. 
16. Kumar N, Chauhan LS. Synthesis and anticonvulsant activity of some flavones incorporated hydrazide derivatives. Int J Pharm Clin Res. 2015;7(4):317-322.

17. Verma M, Pandeya SN, Singh KN, Stables JP. Anticonvulsant activity of Schiff bases of isatin derivatives. Acta Pharm. 2004;54(1):49-56.

18. E1-Azab AS, E1Tahir KE. Design and synthesis of novel 7-aminoquinazoline derivatives: antitumor and anticonvulsant activities. Bioorg Med Chem Lett. 2012;22(5):1879-1885.

19. Nelson M, Yang M, Dowle AA, Thomas JR, Brackenbury WJ. The sodium channel-blocking antiepileptic drug phenytoin inhibits breast tumour growth and metastasis. Mol Cancer. 2015;14:13.

20. Kers I, Csjernyik G, Macsari I, et al. Structure and activity relationship in the (S)-N-chroman-3-ylcarboxamide series of voltage-gated sodium channel blockers. Bioorg Med Chem Lett. 2012;22(17):5618-5624.

21. Rawat P, Verma SM. Synthesis and pharmacological evaluation of 6-hydroxy-2,5,7,8-tetramethyl-N'-(2-oxoindolin-3-ylidene)chroman2-carbohydrazide derivatives as antimicrobial agents. J Chem Pharm Res. 2016;8(3):149-154.

22. Hyatt JA. Convenient preparation of 2,7,8-trimethyl-6-hydroxychroman2-carboxylic Acid ( $\mathrm{X}$-Trolox). Synth Commun. 2008;38(1):8-14.

23. Skehan P, Storeng R, Scudiero D, et al. New colorimetric cytotoxicity assay for anticancer-drug screening. J Natl Cancer Inst. 1990; 82(13):1107-1112.
24. Krall RL, Penry JK, White BG, Kupferberg HJ, Swinyard EA. Antiepileptic drug development: II. Anticonvulsant drug screening. Epilepsia. 1978;19(4):409-428.

25. Porter RJ, Cereghino JJ, Gladding GD, et al. Antiepileptic drug development program. Cleve Clin Q. 1984;51(2):293-305.

26. Dunham NW, Miya TS. A note on a simple apparatus for detecting neurological deficit in rats and mice. J Am Pharm Assoc. 1957;46(3): 208-209.

27. Malik S, Ahuja P, Sahu K, Khan SA. Design and synthesis of new of 3-(benzo[d]isoxazol-3-yl)-1-substituted pyrrolidine-2, 5-dione derivatives as anticonvulsants. Eur J Med Chem. 2014;84:42-50.

28. Koufaki M, Kiziridi C, Papazafiri P, et al. Synthesis and biological evaluation of benzopyran analogues bearing class III antiarrhythmic pharmacophores. Bioorg Med Chem. 2006;14(19):6666-6678.

29. Lopez GV, Blanco F, Hernandez P, et al. Second generation of $\alpha$-tocopherol analogs-nitric oxide donors: synthesis, physicochemical, and biological characterization. Bioorg Med Chem. 2007; 15(18):6262-6272.

30. Fang Y, Sun C, Liu D, Wang S, Quan Z. Synthesis and anticonvulsant activity evaluation of 3-alkoxy-4-(4-(hexyloxy/heptyloxy)phenyl)-4H1,2,4-triazole. Iran J Pharm Res. 2015;14(1):77-87.
Drug Design, Development and Therapy

\section{Publish your work in this journal}

Drug Design, Development and Therapy is an international, peerreviewed open-access journal that spans the spectrum of drug design and development through to clinical applications. Clinical outcomes, patient safety, and programs for the development and effective, safe, and sustained use of medicines are the features of the journal, which

\section{Dovepress}

has also been accepted for indexing on PubMed Central. The manuscript management system is completely online and includes a very quick and fair peer-review system, which is all easy to use. Visit http://www.dovepress.com/testimonials.php to read real quotes from published authors. 